Article

\title{
Degradable Cross-Linked Nanoassemblies as Drug Carriers for Heat Shock Protein 90 Inhibitor 17- $\mathrm{N}$-Allylamino-17-demethoxy- geldanamycin
}

\author{
Andrei Ponta, Shanjida Akter and Younsoo Bae * \\ Department of Pharmaceutical Sciences, College of Pharmacy, University of Kentucky, \\ 789 South Limestone, Lexington, KY 40536-0596, USA \\ * Author to whom correspondence should be addressed; E-Mail: younsoo.bae@uky.edu; \\ Tel.: +1-859-323-6649; Fax: +1-859-257-7564.
}

Received: 8 August 2011; in revised form: 7 September 2011 / Accepted: 19 September 2011 / Published: 26 September 2011

\begin{abstract}
Cross-linked nanoassemblies (CNAs) with a degradable core were prepared for sustained release of 17-N-allylamino-17-demethoxygeldanamycin (17-AAG), a potent inhibitor of heat shock protein 90 (HSP90). The particle size of CNAs ranged between 100 and $250 \mathrm{~nm}$, which changed depending on the cross-linking yields and drug entrapment method. CNAs with a $1 \%$ cross-linking yield entrapped 17-AAG in aqueous solutions, yet degraded in $3 \mathrm{hrs}$. CNAs entrapped 5.2 weight $\%$ of $17-\mathrm{AAG}$ as the cross-linking yield increased to $10 \%$, retaining more than $80 \%$ of particles for $24 \mathrm{hrs}$. CNAs with drugs entrapped after the cross-linking reactions were $100 \mathrm{~nm}$ and remained stable in both $\mathrm{pH} 7.4$ and 5.0, corresponding to the physiological, tumoral, and intracellular environments. Drug was completely released from CNAs in $48 \mathrm{hrs,} \mathrm{which} \mathrm{would} \mathrm{potentially} \mathrm{maximize} \mathrm{drug}$ delivery and release efficiency within tumor tissues. Drug release patterns were not negatively affected by changing the cross-linking yields of CNAs. CNAs entrapping 17-AAG suppressed the growth of human non-small cell lung cancer A549 cells as equally effective as free drugs. The results demonstrated that CNAs would be a promising formulation that can be used in aqueous solutions for controlled delivery and release of 17-AAG.
\end{abstract}

Keywords: drug delivery; controlled drug release; nanoassemblies; heat shock protein 90; cancer chemotherapy 


\section{Introduction}

A heat shock protein (HSP) is a molecular chaperone that refolds damaged proteins in the cell [1,2]. Protein refolding is responsible for cell survival under stressed conditions, and most cancer cells take advantage of the HSP-mediated cell protection machinery by overexpressing HSPs [3]. HSPs are involved in refolding more than 300 types of proteins, often called client proteins [4], which include not only essential proteins used for the cellular signaling cascade but also all six hallmarks of cancer (self-sufficient growth, insensitivity to anti-growth, tissue invasion, limitless reproduction, sustained angiogenesis, and apoptosis evasion).

HSPs work in the cell as complexes, and different family members are involved [5,6]. Among HSPs, $90 \mathrm{kDa}$ HSP (HSP90) plays an important role in regulating the complex formation and subsequent biological action [7]. In an effort to stop HSP functions selectively in cancer cells, a large number of HSP90 inhibitors have been developed. 17-N-Allylamino-17-demethoxygeldanamycin (17-AAG) is one of the promising HSP90 inhibitors, derivatized from a benzoquinone ansamycin antibiotic geldanamycin [8]. 17-AAG is effective in the low nanomolar concentration range in suppressing cancer cell growth. It is less toxic than geldanamycin, a chemotherapeutic agent that failed preclinical trials due to serious hepatotoxicity [9]. Low water-solubility and poor bioavailability are two major issues that limit clinical applications of 17-AAG [10].

Drug delivery systems using nanoparticles (nanoparticulate drug delivery) have drawn attention in recent years as technology that improves water-solubility, tumor preferential accumulation, and controlled release of anticancer drugs [11-13]. Most anticancer drugs are highly toxic and hardly soluble in aqueous solutions. Solubilizers, such as DMSO, Cremophor EL and other surfactants, are frequently used to prepare drug formulations, yet these formulations often cause adverse effects in cancer patients (skin reactions, headache, nausea, vomiting, diarrhea, and allergic reactions) [14].

Polymer micelles are one of the most promising drug carriers used for nanoparticulate drug delivery. They are being tested in multiple clinical trials in several countries $[15,16]$. We have been developing multifunctional polymer micelles to enhance therapeutic efficacy and reduce toxicity of various therapeutic agents [17-23]. Polymer micelles are nanoscale particles $(<200 \mathrm{~nm})$ comprising a hydrophobic core enveloped by a hydrophilic shell. The hydrophobic core acts as a nano compartment for drug loading while the hydrophilic shell improves the particle solubility and prevents protein adsorption that triggers the immune response in the body. Our previous studies demonstrated that polymer micelles carried anticancer drugs to tumor tissues preferentially, reducing toxicity in animal tumor models [19]. Polymer micelles appeared to be a versatile platform for geldanamycin analogues alone and in combination with other anticancer drugs [22]. Chemical conjugation between drug molecules was used in these studies to prevent burst drug release and to fine tune the overall drug release patterns by using degradable linkers such as ester and hydrazone bonds [23,24]. In comparison to other cancer drugs, 17-AAG has no functional groups that can be used for chemical conjugation to drug carriers without altering its biological activity (Figure 1). In this study, therefore, we prepared a cross-linked nanoassembly (CNA) that has a degradable core in which 17-AAG can be physically entrapped and preserved stably in aqueous solutions for a prolonged time period. This novel approach is expected to deliver 17-AAG to tumor tissues efficiently without complicated synthesis of drug analogues for chemical conjugation. 
Figure 1. Preparation of CNAs entrapping 17-AAG.

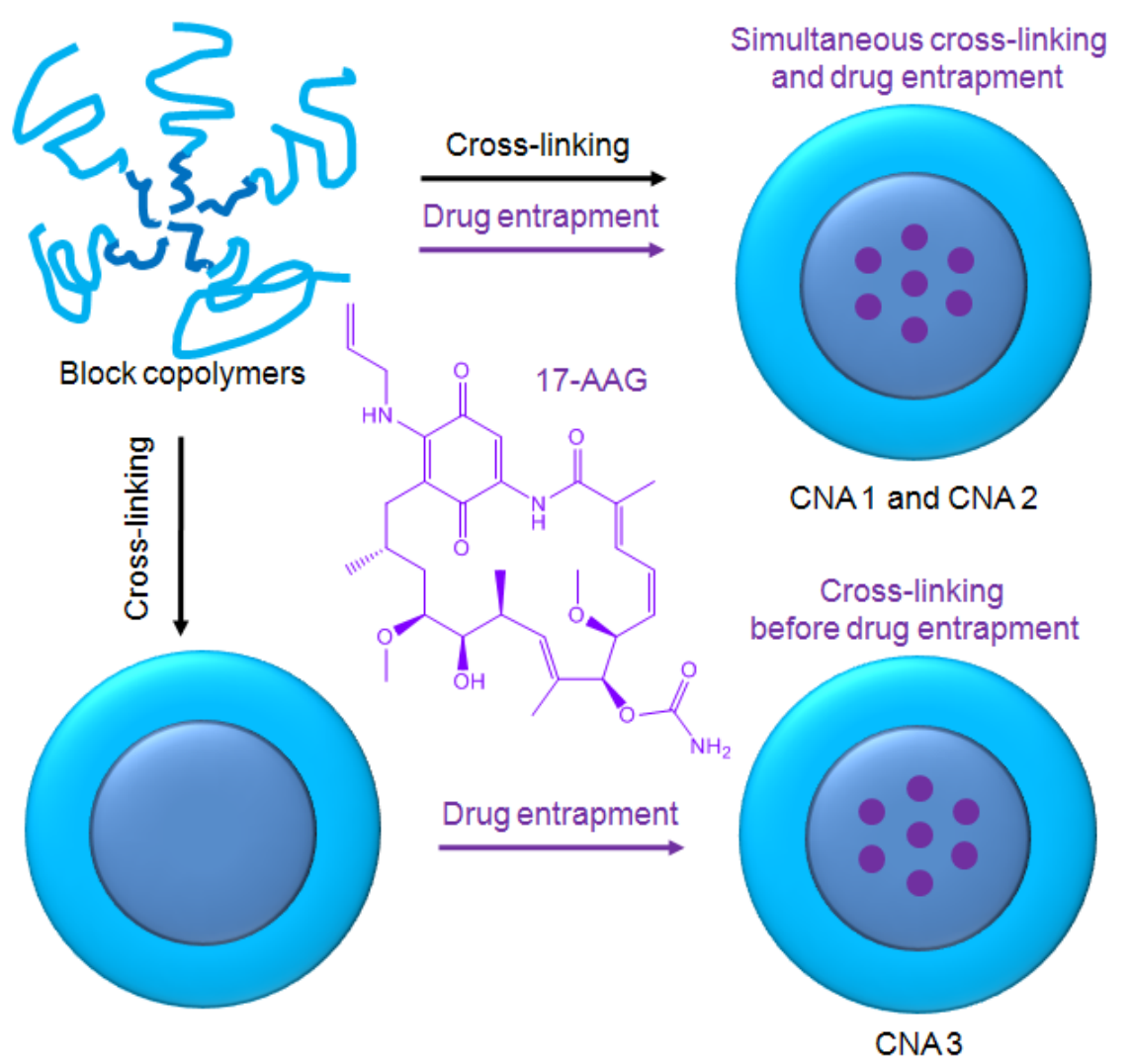

CNAs were previously shown to improve particle stability and entrap drug effectively without changing the particle properties before and after drug entrapment [25]. We prepared CNAs for 17-AAG by cross-linking water soluble poly(ethylene glycol)-poly(aspartate hydrazide) block copolymers with undecanedione, introducing degradable hydrazone cross-linkers (Scheme 1). Drugs were entrapped in the CNAs with different cross-linking ratios during and after the cross-linking reactions. This article reports nanoparticulate properties of CNAs entrapping 17-AAG, which provide a better understanding of this novel drug delivery formulation for its further development in pre-clinical and clinical development.

\section{Experimental Section}

\subsection{Chemicals and Cell-Line}

$\alpha$-Methoxy- $\omega$-amino poly(ethylene glycol) (PEG, MW = 5,000) was purchased from NOF Corporation (Tokyo, Japan). Anhydrous tetrahydrofuran, anhydrous hexane, anhydrous dimethylsulfoxide (DMSO), anhydrous hydrazine, benzene, anhydrous ethyl ether, L-aspartic acid $\beta$-benzyl ester, triphosgene, and 3,9-undecadione were purchased from Sigma-Aldrich Inc. (St. Louis, MO, USA). Regenerated cellulose dialysis bags with 6-8,000 molecular weight cut off (MWCO), Slide-A-Lyzer ${ }^{\circledR}$ dialysis cassettes with 10,000 MWCO, acetate buffer solution, and phosphate buffer solution were purchased from Fisher Scientific (Pittsburg, PA, USA). 17-(Allylamino)-17demethoxygeldanamycin (17-AAG) was purchased from LC Laboratories (Woburn, MA, USA). The 
lung cancer cell line A549, and F12K media were purchased from ATCC (Manassas, VA, USA). Fetal bovine serum (FBS) was purchased from Atlanta Biological (Atlanta, GA, USA).

\subsection{Cross-Linked Nanoassembly Synthesis}

Poly(ethylene glycol)-poly(aspartate hydrazide) [PEG-p(Asp-Hyd)] block copolymers were synthesized as reported previously [18,23] (Scheme 1). Briefly, L-aspartic acid $\beta$-benzyl ester was reacted with triphosgene to prepare N-carboxyanhydride (NCA) monomers, which were subsequently polymerized by using PEG as a macroinitiator. Synthesized PEG-poly( $\beta$-benzyl L-aspartate) block copolymers were reacted with anhydrous hydrazine to introduce hydrazide groups. Activated block copolymers were purified by ether precipitation, and freeze-dried to collect PEG-p(Asp-Hyd) block copolymers comprising of $5 \mathrm{kDa}$ PEG and 33 repeating units of aspartic acid. Nanoassemblies (CNAs) were subsequently prepared by reacting PEG-p(Asp-Hyd) and 3,9-undeca-dione in DMSO at $50 \mathrm{mg} / \mathrm{mL}$. The reaction was allowed to proceed for two days at $37^{\circ} \mathrm{C}$. The cross-linking degree was aimed at 1 and $10 \%$ by adjusting the molar ratios between hydrazide groups of PEG-p(Asp-Hyd) and ketone groups of 3,9-undecanedione CNAs were purified and collected. Samples of CNAs with 10\% cross-linking were kept for separately for characterization. Remaining CNAs were used for drug entrapment as described below.

Scheme 1. Synthesis of block copolymers and CNAs.<smiles>COCCOCCCNC(=O)C(N)CC(=O)OCc1ccccc1</smiles><smiles>COCCOCCCNC(=O)C(CC(=O)NN)NN</smiles>

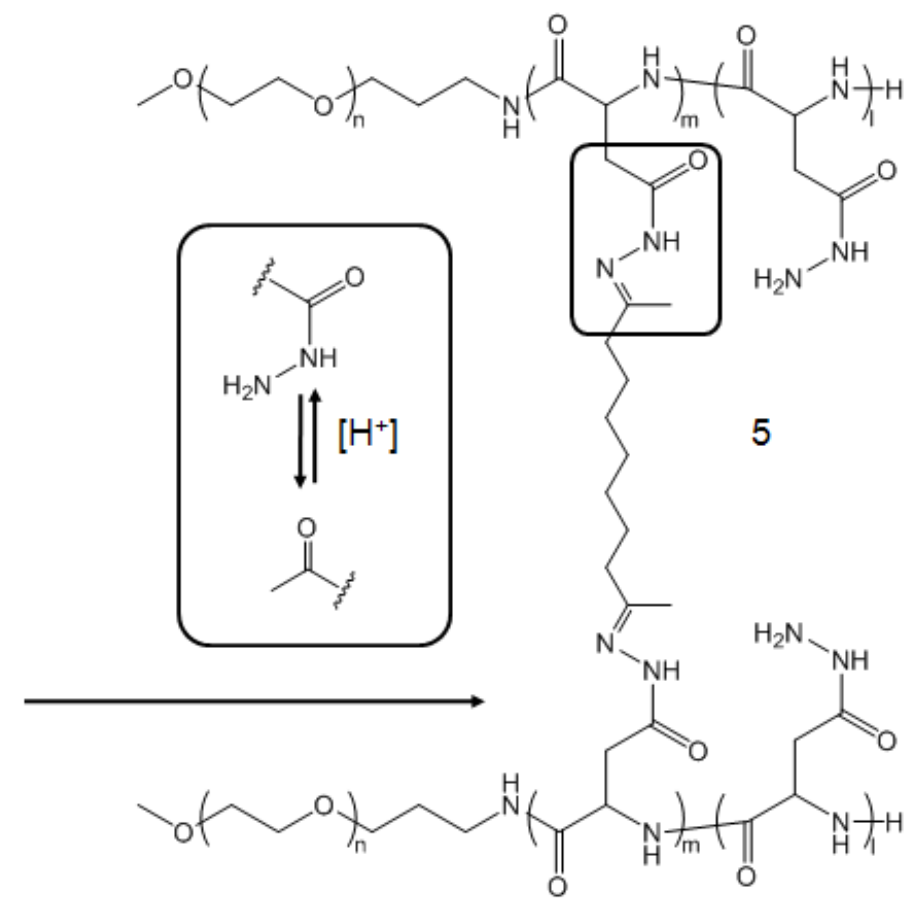




\subsection{Drug Entrapment}

Drug was entrapped in CNAs by two methods. One was to entrap drugs while conducting the block copolymer cross-linking reactions. The other method was to prepare CNAs first and allow the CNAs to absorb drug later. For simultaneous drug entrapment, PEG-p(Asp-Hyd) (200 mg, $21.5 \mu \mathrm{M})$ and 17-AAG $(50 \mathrm{mg}, 85.5 \mu \mathrm{M})$ were dissolved in DMSO at $50 \mathrm{mg} / \mathrm{mL}$ in a scintillation vial. Undecanedione was separately dissolved in DMSO, and subsequently added to the block copolymer drug mixture. The amount of undecadione was adjusted according to the cross-linking yields ( 1 or $10 \%$ ). The reaction was allowed to proceed for two days at $37^{\circ} \mathrm{C}$. The final DMSO solution was diluted using deionized (DI) water in preparation for filtration using a $0.22 \mu \mathrm{M}$ filter. Immediately after filtration, products were dialyzed for six hours, against DI water using a regenerated cellulose membrane (MWCO 6-8,000). Replacing water frequently led to the removal of free 17-AAG, DMSO, and undecadione. The drug-loaded CNAs were collected after freeze drying from water. CNAs entrapping drugs after cross-linking reactions were prepared by mixing the CNAs and 17-AAG in DMSO. The mixture was kept at $37{ }^{\circ} \mathrm{C}$ for two days. The solutions were filtered $(0.22 \mu \mathrm{m})$ and dialyzed (MWCO 6-8,000). Products were collected by freeze-drying. Drug loading was determined using a SpectraMax M5 (Molecular Devices, Sunnyvale, CA, USA), equipped with SoftMaxPro software. 17-AAG was quantified at $336 \mathrm{~nm}$.

\subsection{Particle Stability Test}

Particle stability of CNAs was tested at $\mathrm{pH} 7.4$ and 5.0 over $48 \mathrm{~h}$ periods $(0,1,3,6,24$, and $48 \mathrm{hrs})$. CNAs $(2 \mathrm{mg} / \mathrm{mL})$ were dissolved in acetate buffer solution $(\mathrm{pH} 5.0,10 \mathrm{mM})$ or phosphate buffer solution ( $\mathrm{pH} 7.4,10 \mathrm{mM}$ ). Particle size and intensity were observed by a Zetasizer Nano-ZS (Malvern, Worcestershire, UK) equipped with He-Ne laser $(4 \mathrm{~mW}, 633 \mathrm{~nm})$ light source configured with $173^{\circ}$ light scattering angle.

\subsection{Drug Release Experiments}

CNA solutions were prepared by dissolving the freeze-dried CNA powders in aqueous solutions at pH 7.4 and 5.0. An initial sample was taken from the solution for the zero hour time point. The remaining CNA solution was split into two equivalent parts and place into Slide-A-Lyzer ${ }^{\circledR}$ (Thermo Scientific, Rockford, IL, USA) dialysis cassettes $(\mathrm{MWCO}=10,000)$. The cassettes were in turn placed in $4.0 \mathrm{~L}$ of $10 \mathrm{mM}$ buffer solutions. Temperature was maintained at a constant $37{ }^{\circ} \mathrm{C}$. At specific intervals $(1,3,6,24$, and $48 \mathrm{hrs}), 150 \mu \mathrm{L}$ of sample solution was removed from the dialysis cassettes for UV-Vis analysis. Each drug release experiment was repeated three times.

\subsection{Cytotoxicity Assays}

The human non-small cell lung cancer cell line A549 was used to determine the cytotoxicity of 17-AAG alone as well as the CNA formulations. Sample stock solutions were prepared at a concentration of $10 \mathrm{mM}$ with respect to $17-\mathrm{AAG}$, as confirmed by UV-Vis analysis. Serial dilutions were then prepared with the lowest concentration $10 \mathrm{nM}$. A549 cells were seeded in a 96 well plate (5,000 cells/well) in $100 \mu \mathrm{L}$ of F12K media containing $10 \%$ FBS. After $24 \mathrm{~h}$, the media were removed, 
and replaced with drug containing media with a maximum DMSO content of $1 \%$. Cells were kept at $37{ }^{\circ} \mathrm{C}$ and $5 \% \mathrm{CO}_{2}$ for 72 hours. Cell viability was assessed using a resazurin assay that indicates mitochondrial metabolic activity in live cells. $10 \mu \mathrm{L}$ of a $1 \mathrm{mM}$ resazurin solution in PBS was added to the vehicle- and drug-treated cells at the end of the treatment period. Cell viability was determined three hours later by reading the fluorescence at $560 \mathrm{~nm}(\mathrm{Ex}) / 590 \mathrm{~nm}(\mathrm{Em})$. The fluorescence signals were quantified using a Spectramax M5 plate reader (Molecular Devices) equipped with a SoftMaxPro software. Cytotoxicity was determined by calculating the half maximal inhibitory concentration (IC50) of each sample with Prism software.

\subsection{Statistics}

Each experiment was performed in at least triplicates. Data were recorded as average \pm standard deviation. Microsoft Excel (2007) and Prism software were used for data analysis.

\section{Results and Discussion}

\subsection{Block Copolymer and CNA Synthesis}

The synthesis process of PEG-p(Asp-Hyd) is shown in Scheme 1. Ring opening polymerization of NCA produced PEG-poly( $\beta$-benzyl L-aspartate) [PEG-PBLA] block copolymers. Products contained 33 BLA repeating units, which was determined by ${ }^{1} \mathrm{H}-\mathrm{NMR}$. This was achieved by comparing the peak areas from PEG (3.5 ppm) and benzyl groups (7.2 ppm). The benzyl groups were completely replaced with hydrazide groups following the aminolysis reaction between PEG-PBLA and hydrazine. The purity of PEG-p(Asp-Hyd) was confirmed as we previously reported [23]. CNAs were prepared by reacting PEG-p(Asp-Hyd) and undecadione. Hydrazide groups on the block copolymers formed an acid-labile hydrazone bond with undecadione. No additional chemicals were used during the cross-linking reaction. Aimed cross-linking degree was adjusted by controlling the amount of undecadione used in the reaction. ${ }^{1} \mathrm{H}-\mathrm{NMR}$ was used to confirm the insertion of undecanedione. However, potential side-reactions, such as partial conjugation of undecadione and cross-linking within the same block copolymer chain, could not be identified completely in this study.

\subsection{Particle Size and Drug Entrapment}

Table 1 summarizes the particle size and drug entrapment yields of all CNAs prepared in this study. CNAs with $1 \%$ cross-linking had an average particle size of $177.6 \mathrm{~nm}$. The particle size distribution of CNAs with $1 \%$ cross-linking (CNA 1) was broad, but no distinctive populations of particles were observed. The particle size of CNAs increased to $183.5 \mathrm{~nm}$ as the core cross-linking yield became $10 \%$ (CNA 2). CNA 2 showed a narrow particle size distribution. Higher cross-linking yields seem to be more effective to tether PEG-p(Asp-Hyd) chains without affecting the particle size. CNA1 entrapped $5.2 \mathrm{wt} \%$ of $17-\mathrm{AAG}$. The drug entrapment yield was increased for CNA 2 to $15.7 \mathrm{wt} \%$. CNA 2 entrapped three times more drugs compared to CNA 1 although th e particle size remained the same. The drug entrapment method changed the particle size of CNAs. CNAs to which drugs were entrapped after cross-linking (CNA 3) were smaller than CNA 2. The particle size of CNA 3 was $109.4 \mathrm{~nm}$, which was two-fold smaller than that of CNA 2 where drugs were entrapped during cross-linking. 
Entrapping drugs in CNA 3 achieved $14.1 \mathrm{wt} \%$ drug loading, which was comparable with the drug entrapment yield in CNA 2. Blank CNAs with 10\% cross-linking had a particle size of $29.4 \mathrm{~nm}$ with a narrow particle size distribution. After drug loading, CNA particle size, irrespective of the cross-linking degree, increased to more than $100 \mathrm{~nm}$. These results suggest that the core of CNAs can still swell even at the $10 \%$ cross-linking yield during drug entrapment.

Table 1. Characterization of CNAs entrapping 17-AAG.

\begin{tabular}{cccc}
\hline \multirow{2}{*}{ CNA } & \multicolumn{2}{c}{ Particle Size (nm) } & \multirow{2}{*}{ Drug Loading (wt \%) } \\
\cline { 2 - 3 } & pH 7.4 & pH 5.0 & 5.4 \\
CNA 1 & $177.6 \pm 94.5$ & $177.4 \pm 98.4$ & 14.9 \\
CNA 2 & $183.5 \pm 3.7$ & $170.6 \pm 5.6$ & 14.1 \\
CNA 3 & $109.4 \pm 3.3$ & $98.3 \pm 15.5$ & \\
\hline
\end{tabular}

\subsection{Particle Stability}

Particle stability of CNAs was characterized at $\mathrm{pH} 7.4$ and 5.0, which correspond to the physiological condition ( $\mathrm{pH}$ 7.4) and the acidic in vivo environments such as tumor tissues ( $\mathrm{pH}$ 6.5) and lysosomes $(5<\mathrm{pH}<6.5)$. CNAs without 17 -AAG maintained a particle size of about $30 \mathrm{~nm}$ irrespective of $\mathrm{pHs}$. Particle size remained relatively unchanged over a $48 \mathrm{~h}$ period in both $\mathrm{pH} 7.4$ and 5.0 (Figure 2). It is noticeable that only CNA3 showed a slight change in particle size in different pHs.

Figure 2. Time-dependent changes in particle sizes and light scattering intensity of CNAs.
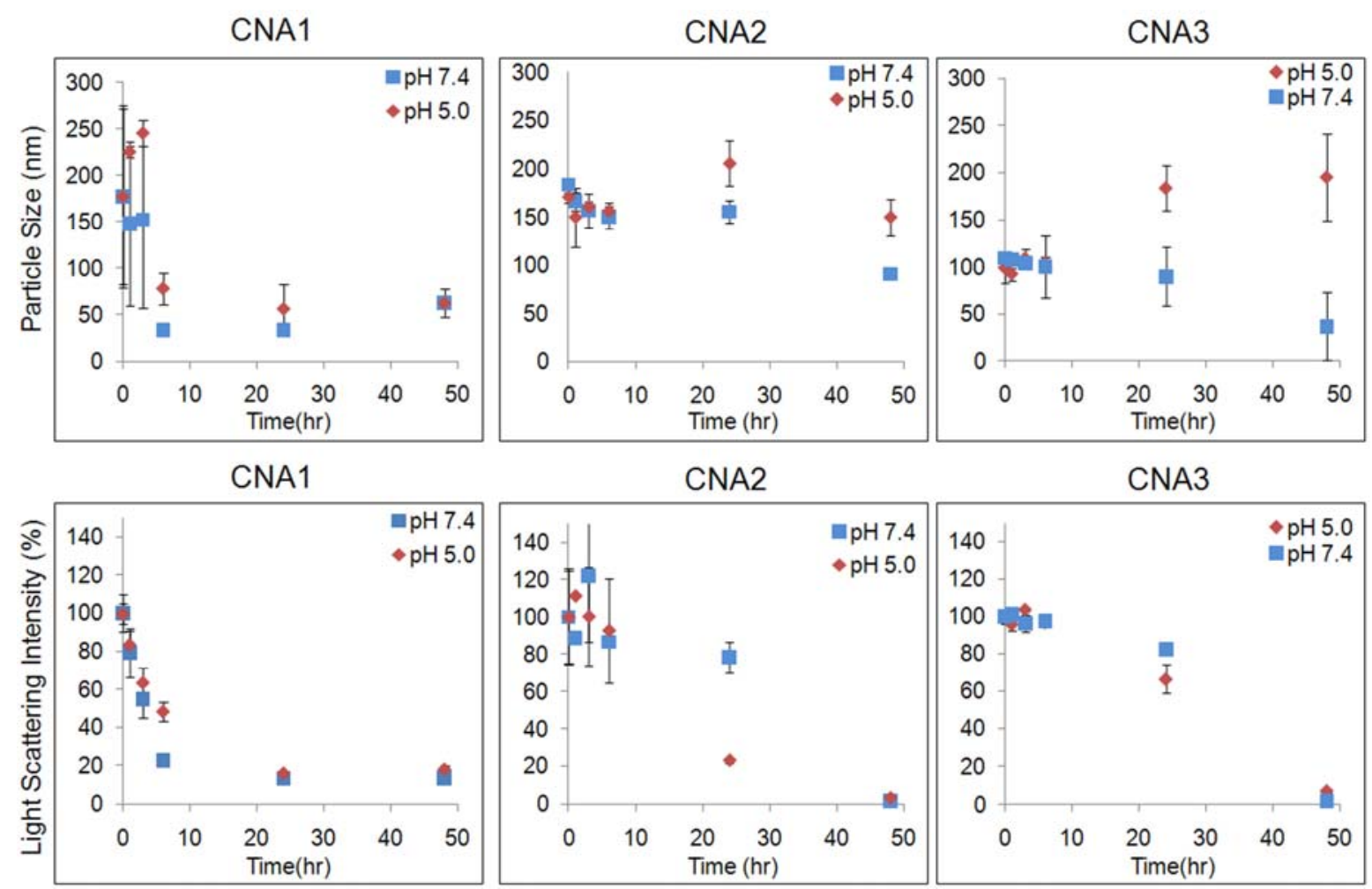

Light scattering intensity was also observed in order to ensure that particles did not degrade over time. Interestingly, at $\mathrm{pH} 7.470 \%$ of the initial light scattering was observed after $3 \mathrm{~h}$, but this 
intensity was maintained until the $48 \mathrm{~h}$ time point. At $\mathrm{pH} 5.0$, only $20 \%$ of the initial light scattering intensity was lost during the duration of the experiment. It was apparent that CNAs remained present after a $48 \mathrm{~h}$ period, at both $\mathrm{pH} 5.0$ and 7.4. The initial particle size of drug loaded CNAs was similar at both $\mathrm{pH} 7.4$ and 5.0, indicating that CNAs can remain stable in the blood and tumor tissues following intravenous injections. CNA 1 degraded rapidly, and only $20 \%$ of initial light scattering intensity was observed after 3 hrs. CNA 2 improved the particle stability, retaining more than $80 \%$ of light scattering intensity at a constant particle size. Degradation of CNA 2 was accelerated at pH 5.0, while the CNAs remained stable at $\mathrm{pH} 7.4$ up to $24 \mathrm{hrs}$. When drugs were entrapped in CNAs after cross-linking, particle stability was improved at $\mathrm{pH} 5.0$ as well as 7.4, retaining more than $60 \%$ of CNA 3 in the acidic environment. All CNAs degraded completely over $48 \mathrm{~h}$ at $\mathrm{pH} 7.4$ and 5.0. These results demonstrate that drug entrapment after preparing empty CNAs is effective to prepare stable CNAs that can preserve drug molecules in physiological and acidic tumor environments for prolonged time.

\subsection{Drug Release Experiments}

Figure 3 shows drug release patterns from CNAs incubated at $\mathrm{pH} 7.4$ and 5.0. CNA 1 released more than $80 \%$ of $17-A A G$ in $6 \mathrm{hrs}$. The cross-linking yields did not slow down the drug release from CNAs. CNA 2 and CNA 3 with 10\% cross-linking yields) showed a similar drug release pattern in comparison to CNA 1 ( $1 \%$ cross-linking). The drug entrapment method did not change the drug release patterns, neither accelerating nor slowing down drug release at $\mathrm{pH} 7.4$ and 5.0. Particle stability and drug release patterns were inconsistent, because CNA 2 and 3 that remained stable for 24 hrs released drugs as quickly as CNA 1 that degraded in $3 \mathrm{hrs}$. It is surmised that the cross-linked core of CNAs is leaky enough even at a $10 \%$ cross-linking yield for $17-A A G$ to diffuse through the core easily while the drug molecules strongly interact with the core-forming segment of PEG-p(Asp-Hyd). It must be noted that the sampling at $24 \mathrm{~h}$ and $48 \mathrm{~h}$, which both yielded near complete drug release from all CNAs, did not provide further insight in understanding the kinetics of drug release, although the time points in Figures 2 and 3 were matched for drug release and particle stability studies. The release data for free 17-AAG would be also necessary to validate our findings more accurately as suggested by other research groups [26]. However, our attempts were unsuccessful to determine accurate concentrations of free 17-AAG in a dialysis bag due to drug precipitation. Further studies are necessary to elucidate how 17-AAG molecules are present in the core of CNAs.

\subsection{Cytotoxicity Assays}

Biological activity of drug-entrapped CNAs was tested in A549 cell lines, using free 17-AAG in DMSO as a positive control. CNA 2 and 3 had $\mathrm{IC}_{50}$ values of $342 \mathrm{nM}$ and $196 \mathrm{nM}$, respectively, following sample exposure to A549 for $72 \mathrm{hrs}$ (Figure 4).

CNA 1 had an $\mathrm{IC}_{50}$ of $400 \mathrm{nM}$, indicating that cross-linking degree does not affect the activity of 17-AAG. Free 17-AAG showed an $\mathrm{IC}_{50}$ value of $284 \mathrm{nM}$ under the sample conditions. A one-way ANOVA revealed that there was no statistical significance among the $\mathrm{IC}_{50}$ values of free drug and drug-entrapped CNAs. 
Figure 3. Drug release patterns of CNAs entrapping 17-AAG.

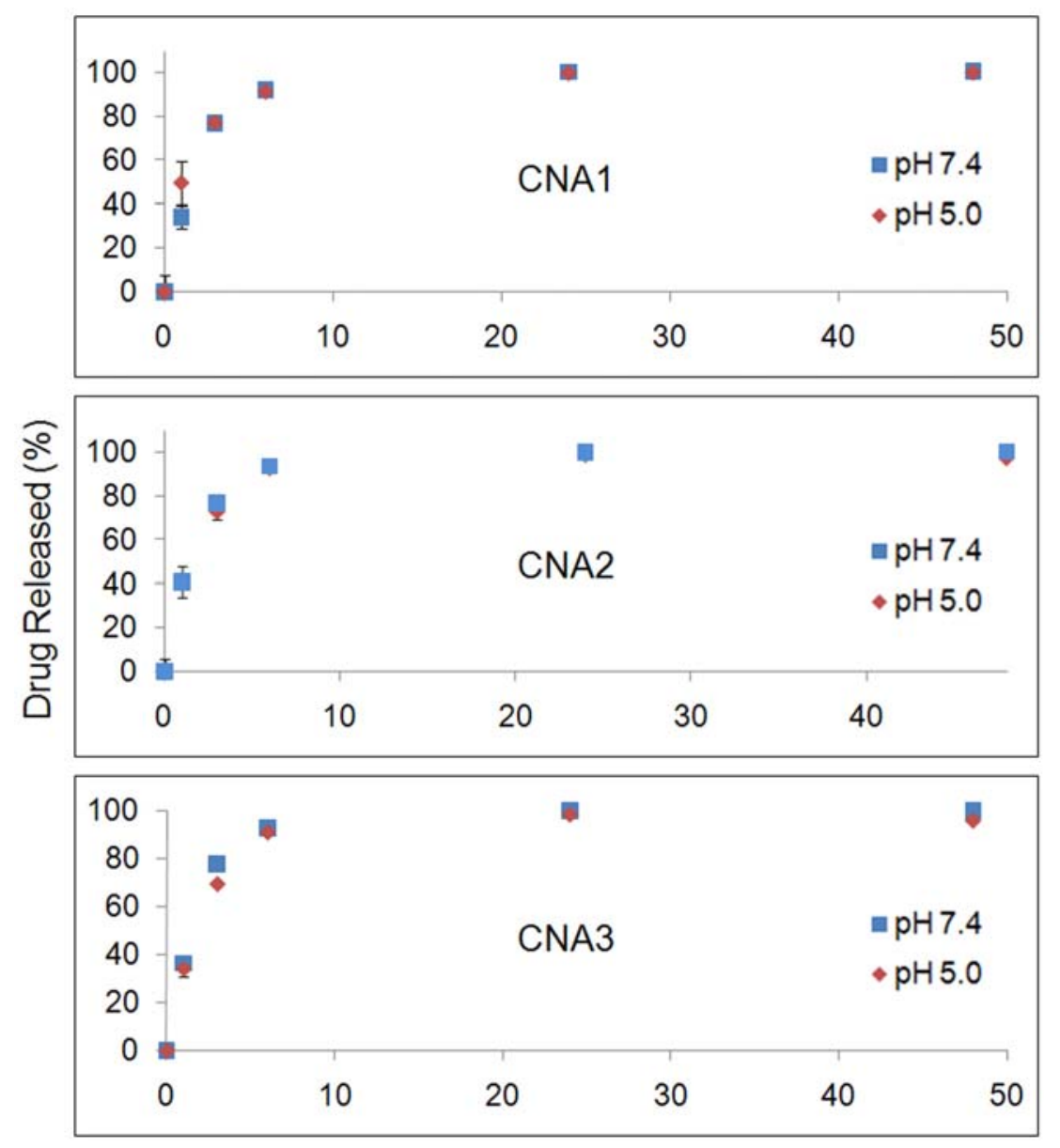

Figure 4. $\mathrm{IC}_{50}$ values of CNAs entrapping $17-\mathrm{AAG}$ in A549 cell line.

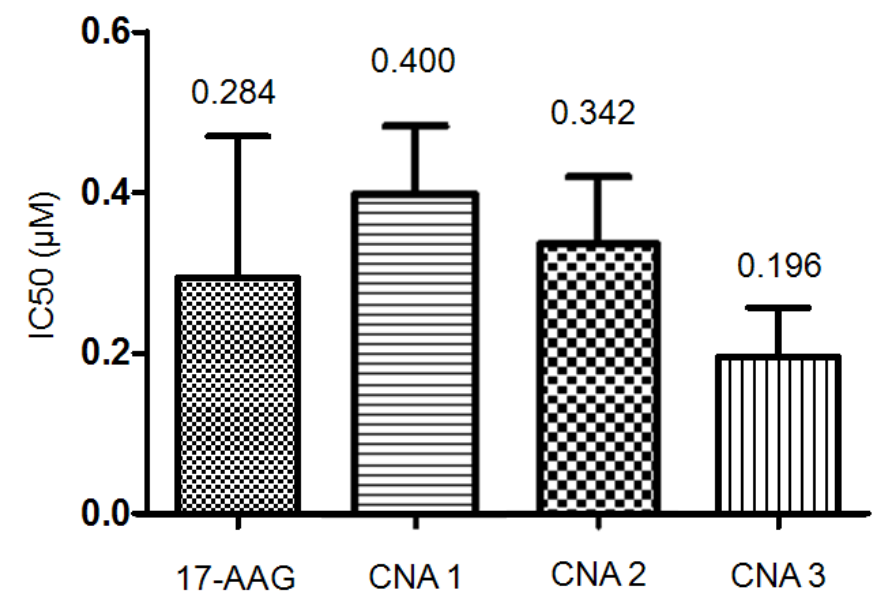

Interestingly, CNAs with drugs entrapped after cross-linking induced cytostatic effects on the cells, and more than $30 \%$ cells were still alive even at $100 \mu \mathrm{M}$ (Figure 5). Other drug-entrapped CNAs and free 17-AAG caused complete cell death at $100 \mu \mathrm{M}$, although the overall viability curves looked similar up to $10 \mu \mathrm{M}$. These results suggest that CNA formulations can be used to change biological efficacy of 17-AAG, although further investigation is necessary. 
Figure 5. Viability curves of A549 cells exposed to CNAs entrapping 17-AAG.

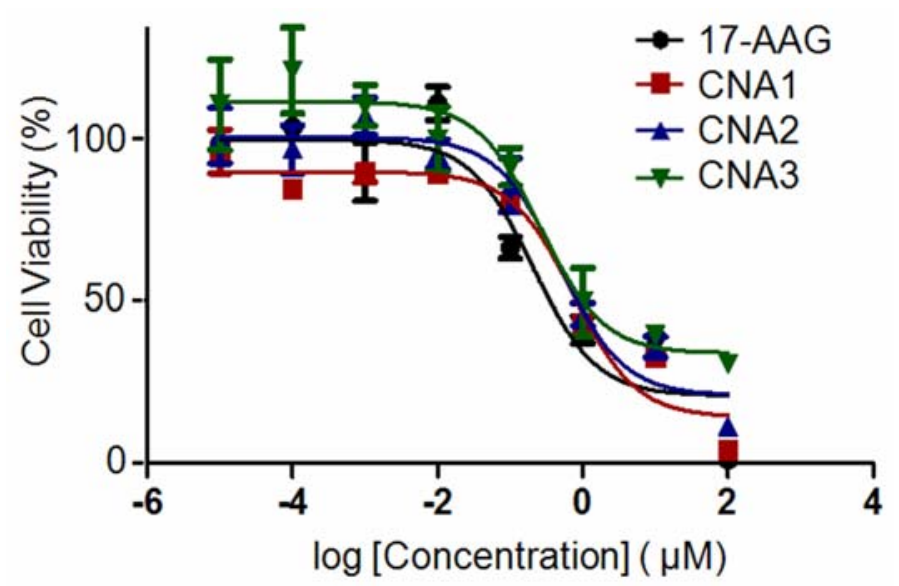

\section{Conclusions}

In this study, degradable CNAs were prepared as a delivery carrier for 17-AAG. The cross-linking yield and drug entrapment method were tested to prepare drug-entrapped CNAs with structural uniformity, particle stability, and drug release patterns relevant to clinical applications. CNAs showed high drug entrapment yields (5.2 15.7 wt \%) and complete drug releases in $48 \mathrm{hrs}$. CNAs had narrow particle size distribution as the cross-linking yield increased from 1 to $10 \%$. The $10 \%$ cross-linking yield appeared to stabilize CNAs without affecting the drug release patterns at $\mathrm{pH} 7.4$ and 5.0. CNAs with drugs entrapped after cross-linking of the core were stable, and more than $60 \%$ of CNAs preserved drugs in aqueous solutions at $37{ }^{\circ} \mathrm{C}$ for $24 \mathrm{hrs}$. CNAs released 17-AAG in an active form to cause cell growth inhibition in cancer cells at the drug concentration similar to that of free drugs. Cancer cells showed differential cellular response (cytotoxic and cytostatic) to CNAs depending on the drug entrapment method. Therefore, CNAs are expected to provide an efficient and convenient nanoscale drug delivery vehicle for 17-AAG and other hydrophobic drugs that have issues such as low water solubility, poor bioavailability, and limited drug accumulation in tumors.

\section{Acknowledgements}

This research is supported by the Kentucky Lung Cancer Research Program.

\section{References}

1. Chiosis, G.; Neckers, L. Tumor selectivity of hsp90 inhibitors: The explanation remains elusive. ACS Chem. Biol. 2006, 1, 279-284.

2. Ferrarini, M.; Heltai, S.; Zocchi, M.R.; Rugarli, C. Unusual expression and localization of heat-shock proteins in human tumor-cells. Int. J. Cancer 1992, 51, 613-619.

3. Young, J.C.; Moarefi, I.; Hartl, F.U. Hsp90: A specialized but essential protein-folding tool. J. Cell Biol. 2001, 154, 267-273.

4. Hanahan, D.; Olson, P.; Lu, J.; Zhang, H.; Shai, A.; Chun, M.G.; Wang, Y.C.; Libutti, S.K.; Nakakura, E.K.; Golub, T.R. Microrna dynamics in the stages of tumorigenesis correlate with hallmark capabilities of cancer. Genes Dev. 2009, 23, 2152-2165. 
5. Neckers, L.; Xu, W.P. Targeting the molecular chaperone heat shock protein 90 provides a multifaceted effect on diverse cell signaling pathways of cancer cells. Clin. Cancer Res. 2007, 13, 1625-1629.

6. Goetz, M.P.; Toft, D.O.; Ames, M.M.; Erlichman, C. The hsp90 chaperone complex as a novel target for cancer therapy. Ann. Oncol. 2003, 14, 1169-1176.

7. Whitesell, L.; Beliakoff, J. Hsp90: An emerging target for breast cancer therapy. Anticancer Drugs 2004, 15, 651-662.

8. Burrows, F.J.; Kamal, A.; Thao, L.; Sensintaffar, J.; Zhang, L.; Boehm, M.F.; Fritz, L.C. A high-affinity conformation of hsp90 confers tumour selectivity on hsp90 inhibitors. Nature 2003, 425, 407-410.

9. Supko, J.G.; Lu, H.; Jimeno, J.M.; Grant, W.; Faircloth, G.T. Preclinical pharmacology studies with the marine natural product kahalalide f. Clin. Cancer Res. 1999, 5, 3792s-3792s.

10. Younes, A.; Copeland, A.R.; Romaguera, J.; Fayad, L.; Fanale, M.; Faria, S.D.; Medeiros, L.J.; Ivy, S.P. Clinical and biologic activity of the heat shock protein-90 (hsp-90) inhibitor 17-aag in patients with relapsed lymphoma. Blood 2009, 114, 1441-1441.

11. Duncan, R.; Ringsdorf, H.; Satchi-Fainaro, R. Polymer therapeutics-polymers as drugs, drug and protein conjugates and gene delivery systems: Past, present and future opportunities. J. Drug Target. 2006, 14, 337-341.

12. Torchilin, V. Tumor delivery of macromolecular drugs based on the epr effect. Adv. Drug Deliv. Rev. 2011, 63, 131-135.

13. Delcea, M.; Möhwald, H.; Skirtach, A.G. Stimuli-responsive lbl capsules and nanoshells for drug delivery. Adv. Drug Deliv. Rev. 2011, 63, 730-747.

14. Lee, H.; Soo, P.L.; Liu, J.; Butler, M.; Allen, C. Polymeric micelles for formulation of anti-cancer drugs. Nanotechnol. Cancer Ther. 2007, 317-355.

15. Bae, Y.; Kataoka, K. Intelligent polymeric micelles from functional poly(ethylene glycol)poly(amino acid) block copolymers. Adv. Drug Deliv. Rev. 2009, 61, 768-784.

16. Miyata, K.; Christie, R.J.; Kataoka, K. Polymeric micelles for nano-scale drug delivery. React. Funct. Polym. 2011, 71, 227-234.

17. Bae, Y.; Fukushima, S.; Harada, A.; Kataoka, K. Design of environment-sensitive supramolecular assemblies for intracellular drug delivery: Polymeric micelles that are responsive to intracellular ph change. Angew. Chem. Int. Ed. 2003, 42, 4640-4643.

18. Bae, Y.; Jang, W.-D.; Nishiyama, N.; Fukushima, S.; Kataoka, K. Multifunctional polymeric micelles with folate-mediated cancer cell targeting and ph-triggered drug releasing properties for active intracellular drug delivery. Mol. BioSyst. 2005, 1, 242-250.

19. Bae, Y.; Nishiyama, N.; Kataoka, K. In vivo antitumor activity of the folate-conjugated ph-sensitive polymeric micelle selectively releasing adriamycin in the intracellular acidic compartments. Bioconjug. Chem. 2007, 18, 1131-1139.

20. Kano, M.R.; Bae, Y.; Iwata, C.; Morishita, Y.; Yashiro, M.; Oka, M.; Fujii, T.; Komuro, A.; Kiyono, K.; Kaminishi, M.; et al. Improvement of cancer-targeting therapy, using nanocarriers for intractable solid tumors by inhibition of tgf- $\beta$ signaling. Proc. Natl. Acad. Sci. USA 2007, 104, 3460-3465. 
21. Alani, A.W.G.; Bae, Y.; Kwon, G.S. Synthesis and characterization of a micellar drug carrier for the metronomic delivery of paclitaxel. J. Control. Release 2008, 132, e19-e20.

22. Bae, Y.; Alani, A.W.G.; Rockich, N.C.; Lai, T.S.Z.C.; Kwon, G.S. Mixed ph-sensitive polymeric micelles for combination drug delivery. Pharm. Res. 2010, 27, 2421-2432.

23. Ponta, A.; Bae, Y. Peg-poly(amino acid) block copolymer micelles for tunable drug release. Pharm. Res. 2010, 27, 2330-2342.

24. Alani, A.W.G.; Bae, Y.; Rao, D.A.; Kwon, G.S. Polymeric micelles for the ph-dependent controlled, continuous low dose release of paclitaxel. Biomaterials 2010, 31, 1765-1772.

25. Lee, H.J.; Bae, Y. Cross-linked nanoassemblies from poly(ethylene glycol)-poly(aspartate) block copolymers as stable supramolecular templates for particulate drug delivery. Biomacromolecules 2011, 12, 2686-2696.

26. Shin, H.C.; Alani, A.W.; Rao, D.A.; Rockich, N.C.; Kwon, G.S. Multi-drug loaded polymeric micelles for simultaneous delivery of poorly soluble anticancer drugs. J. Control. Release 2009, 140, 294-300.

(C) 2011 by the authors; licensee MDPI, Basel, Switzerland. This article is an open access article distributed under the terms and conditions of the Creative Commons Attribution license (http://creativecommons.org/licenses/by/3.0/). 